\title{
Continued spread of HIV among injecting drug users in southern Sichuan Province, China
}

\author{
Lu Yin ${ }^{1}$, Guangming Qin², Han-Zhu Qian*3, Yu Zhu ${ }^{4}$ Wei Hu', Li Zhang1, \\ Kanglin Chen ${ }^{4}$, Yunxia Wang ${ }^{1}$, Shizhu Liu ${ }^{1}$, Feng Zhou ${ }^{1}$, Hui Xing ${ }^{1}$, \\ Yuhua Ruan*1, Ning Wang ${ }^{1}$ and Yiming Shao ${ }^{1}$
}

\begin{abstract}
Address: ${ }^{1}$ State Key Laboratory for Infectious Disease Prevention and Control, and National Center for AIDS/STD Control and Prevention, Chinese Center for Disease Control and Prevention, 27 Nanwei Road, Xuanwu District, Beijing 100050, China, ${ }^{2}$ Sichuan Provincial Center for Disease Control and Prevention, 6 Zhongxue Road, Wuhou District, Chengdu, Sichuan Province 610031, China, ${ }^{3}$ Department of Medicine/Division of Preventive Medicine, University of Alabama at Birmingham, Room 645, 1717 11 th Avenue South Medical Towers Bld. Birmingham, Alabama 35205, USA and ${ }^{4}$ Xichang Center for STD and Leprosy Control, 5 Chang'an Road, Zhangjiatunxiang, Xichang County, Sichuan Province 615000, China

Email: Lu Yin - translation_lucy@sohu.com; Guangming Qin - qinguangm@sina.com; Han-Zhu Qian - qianhz@uab.edu; Yu Zhu - Lsxchcdc@163.com; Wei Hu - Huwei0302@163.com; Li Zhang - Zhl_73@sohu.com; Kanglin Chen - xcpfz@hotmail.com; Yunxia Wang - Wangyunxia927@sohu.com; Shizhu Liu - liusz118@sohu.com; Feng Zhou - Maple_zhou6911@sohu.com; Hui Xing - xingh@chinaaids.cn; Yuhua Ruan* - yh_ruan@sohu.com; Ning Wang - wangnbj@163.com; Yiming Shao - yshao@bbn.cn

* Corresponding author
\end{abstract}

Published: 8 February 2007

Harm Reduction Journal 2007, 4:6 doi:10.1 186/1477-75/7-4-6
Received: 24 March 2006

Accepted: 8 February 2007

This article is available from: http://www.harmreductionjournal.com/content/4/1/6

(c) 2007 Yin et al; licensee BioMed Central Ltd.

This is an Open Access article distributed under the terms of the Creative Commons Attribution License (http://creativecommons.org/licenses/by/2.0), which permits unrestricted use, distribution, and reproduction in any medium, provided the original work is properly cited.

\author{
Abstract \\ Objective: To estimate HIV prevalence among injecting drug users (IDUs) in a drug trafficking \\ city in southwest Sichuan Province, China.
}

Methods: A total of 3 I 4 IDUs was invited to participate in the cross-sectional survey in 2004 through community outreach recruitment and peer referrals. Blood sample was taken for HIV antibody testing and a structured questionnaire was administered to collect information on socio-demographics, drug using and sexual behaviors.

Results: HIV prevalence among IDUs was $17.8 \%$ (56/3/4), about one half higher than that in previous survey in 2002 (1I.3\%, 43/379). Yi and other minority ethnicity (Odds ratio [OR], 3.I; $95 \%$ confidence interval $[\mathrm{Cl}], \mathrm{I} .7-5.8 ; P<0.00 \mathrm{I})$, and total times of sharing injecting equipments I-9 times versus none, OR, 2.7; 95\% $\mathrm{Cl}$ I.2-6.2; $P=0.02$; and $\geq 10$ times versus none, OR, 7.5; $95 \% \mathrm{Cl}, 3.2-17.7 ; P<0.001$ ) were independent risk factors for HIV infection.

Conclusion: IDUs with high prevalence rates of HIV and equipment sharing behavior in the drug trafficking city may serve a source for further spread of HIV to other areas in China. The increasing trend of HIV epidemic among IDUs underscores the urgency of scaling up interventions. 


\section{Background}

Injecting drug use (IDU) has been the most important risk factor for HIV spread in China. The first HIV outbreak among IDUs was observed in 1989 in a bordering area in Southern Yunnan Province [1]; as of 2002, all 31 provinces, municipalities and autonomous regions in mainland China have reported HIV infection among IDUs [2]. A national epidemiological survey in 16 provinces in 2003 found that, on average, 54\% drug users were IDUs and 7\% IDUs were infected with HIV [Chinese Center for Disease Control, unpublished data]. It is estimated that about $44.3 \%$ of the 650,000 Chinese currently living with HIV/AIDS are drug users [2]. The relative importance of IDU in contribution to total reported HIV/AIDS cases has been declining over years as sexual transmission increases and HIV screening efforts among former plasma donors are enhanced; however, IDU is likely to remain as one major risk as drug use expands from rural bordering areas in Southwestern China to the whole country, especially to urban areas [3].

Xichang is a county-level city in Sichuan Province in Southern China and hosts a population of over 600,000 in total and 380,000 rural residents. The majority of the residents are Han ethnics and approximate 10\% are Yi minority ethnics. Located on one major drug trafficking route [4], Xichang City has about 100,000 migrant people each year and nearly 2,500 registered local drug users. A community-based cross-sectional survey among 379 IDUs in 2002 found that $11.3 \%$ of IDUs in Xichang were infected with HIV [4], and a subsequent 12-month followup study showed a seroconversion rate of 3.17 per 100 person-years [5]. There are virtually no systemic population-based interventions, though some IDUs might receive research-oriented counseling services and even fewer participated in methadone maintenance therapy program which was started in Match 2004. We conducted this cross-sectional study in 2004 to estimate the trend of HIV epidemic among IDUs in this drug trafficking area.

\section{Methods \\ Study design and study population}

This cross-sectional study was conducted between May and July 2004 among IDUs in Xichang City, Sichuan Province. Known IDUs in the community were contacted directly by outreach workers and indirectly through words of mouth to invite IDUs to join the study. Snowball sampling was also employed as a recruitment strategy. A small financial incentive was given to participants who successfully referred peers to the study. Eligibility criteria required that participants be at least 18 years old and have injected drugs at least one time in the past 3 months, be willing to provide informed consent and give blood specimen for HIV testing, and have not participated in the cohort study conducted in $2002[4,5]$, excluding those who were already known to have HIV infection before recruitment. The active injection of drugs was screened by eligibility questionnaire interview and verified by the presence of needle marks or medical record. Xichang Center for STD and Leprosy Control, whereby the study was conducted, has a database for all HIV-infected local residents in Xichang City, and a Participant Information File System (PIFS) software program was developed to record participants' name, locator information and study visits for this study as well as for previous cross-sectional and cohort studies $[4,5]$, so that those who had been tested HIV-positive and/or had participated in the previous studies were identified during the eligibility screening and excluded for this study. After written informed consent was obtained, a structured questionnaire was administered by trained interviewers to collect information socio-demographics, drug use and sharing and sexual behaviors. A blood specimen was collected for testing of HIV antibody. All study participants were given HIV posttesting counseling, and those who were HIV positive were referred to China CARES project in Xichang City which provides comprehensive community-based HIV/AIDS services including voluntary testing and counseling, free antiretroviral therapy and treatment of opportunistic infections. Study protocol and informed consent were approved by the institutional review board of the National Center for AIDS/STD Control and Prevention of the China Center for Disease Control and Prevention.

\section{Laboratory analyses}

Blood specimen was screened for HIV antibody by enzyme-linked immunosorbent assay (ELISA) (Beijing Wantai Biologic Medicine Co., China). Positive ELISA specimen was confirmed by an $\mathrm{HIV}-1 / 2$ Western Blot immune assay (HIV Blot 2.2 WB; Genelabs Diagnositics, Singapore). Samples positive in both tests were considered HIV-positive.

\section{Statistical analysis}

Questionnaire data were double-entered and compared with Epi Data software (Epi Data 3.1 for Windows; The Epi Data Association Odense, Denmark). Then, the data were converted and analyzed using Statistical Analysis System (SAS 9.1 for Windows; SAS Institute Inc., NC). Univariate analyses including Chi-square test, Fisher's exact test, or Mantel-Haenszel chi-square test were performed to evaluate the association of HIV infection with socio-demographic, drug using and sexual behaviors. Those variables significant in univariate analyses $(P \leq$ $0.10)$ were included in a multivariate logistic regression model. The final model was constructed by eliminating non-significant variables in a stepwise manner, identifying variables that were independently associated with HIV seropositivity. 


\section{Results \\ Socio-demographic characteristics, drug using and sexual behaviors}

A total of 316 IDUs were screened, one person did not meet eligibility criteria and one person refused to participate; therefore, 314 subjects were included in the analyses. 247 were referred by seeds or peers (78.7\%), others by outreach workers. The average age was 29 (range 18-46) years; $85.7 \%$ were males; $38.8 \%$ were Yi or other minority ethnics. Education distribution was illiteracy $(14.6 \%)$, primary school (23.6\%) and junior high school (44.9\%). About half (49.4\%) were never married, and $23.6 \%$ were divorced. $61.2 \%$ of subjects were unemployed and $26.0 \%$ owned a house.

The average age of beginning to use drugs, injecting drugs and sharing injection equipments (including needles or syringes) were 22, 25 and 26 years, respectively. In the past 3 months, $64.3 \%$ used heroin as frequently as $\geq 7$ times per week. Of all subjects, $62.7 \%$ reported a history of sharing equipments. Reasons for sharing equipments included: "do not know where to obtain", "inconvenient to obtain", and "high price of syringes and needles." Fiftynine percent of subjects reported having heterosexual activities and none having same-sex contacts in the past six months, and 24.2\% had new sex partners; $20.4 \%$ gave money for sex and $7.3 \%$ received money for sex. Among 67 subjects who had casual and/or commercial sexual partners in the last month, $10.5 \%$ reported using condoms consistently.

\section{HIV prevalence and risk factors}

Of 314 participants, 56 (17.8\%) were infected with HIV. In univariate analyses, factors significantly associated with HIV infection at a level of 0.10 are sex, marital status, ethnicity, total times of sharing injecting equipments in the past, total number of partners sharing injecting equipments in the past, having new partners sharing injecting equipments in last 3 months, sharing needles and syringes, rinse water, and cookers in the last 3 months, having heterosexual intercourses and not having a primary sexual partner in the last 6 months (Table 1, 2, 3).

All variables significant in univariate analyses were entered to multivariate logistic regression models. A final model was constructed with the following variables independently associated with HIV infection: Yi and other minority ethnicity (odds ratio [OR], 3.1; 95\% confidence interval $[\mathrm{CI}], 1.7-5.8 ; \mathrm{P}<0.001)$ and total times of sharing injecting equipments in the past (1-9 times versus none, OR, 2.7; 95\% CI 1.2-6.2; $\mathrm{P}=0.02$; and $\geq 10$ times versus none, $\mathrm{OR}, 7.5$; 95\% CI, 3.2-17.7; $\mathrm{P}<0.001$ ) (Table 4).

\section{Discussion}

Given the same recruitment methods and participation eligibility criteria were employed, this study should be comparable with the first community-based survey in 2002 in estimating HIV prevalence among IDUs in the study site. HIV prevalence rate in $2004(17.8 \%)$ increases by over $50 \%$ than that in $2002(11.4 \%, P=0.02)$, which is consistent with the finding of 3.17 per 100 person-years seroconversion rate among IDU cohort during years of 2002-2003 [5]. The high HIV prevalence rate and prevalent equipment sharing practices are worrisome. Studies have shown that once HIV prevalence among a high-risk IDU population reaches 20\%, HIV epidemic can become self-perpetuating and a modest level of risk behaviors may lead to a substantial rate of infection [6,7]. Furthermore, Xichang is located in one major drug trafficking route, and HIV-infected IDUs in Xichang may become a source for further HIV spread to other geographic areas. China has initiated harm reduction projects including methadone maintenance therapy (MMT) and needle exchange programs. Xichang Center for STD and Leprosy Control is one of the first 8 clinics in the country to provide pilot MMT service since early 2004. Limited experiences show a high drop-out rate of MMT. As China plans to scale up harm reduction projects and expand MMT service to 1000 clinics across the country within five years [8], research is urgently needed to improve the efficacy of MMT itself as well as adding counseling and behavioral intervention components.

The frequency of sharing injecting equipments is an independent risk factor for HIV infection and more times of sharing is associated with higher risk of infection. Beside direct sharing of needles or syringes [9-13], indirect sharing of injecting equipments, including cottons, rinse water, cookers, and front/backloading were also reported as risk factor for HIV infection in other studies [14,15], but were not confirmed in our study. "Do not know where to obtain", "inconvenient to obtain" and "high price of syringes and needles" were reported as reasons of sharing equipments, suggesting that provision of clean equipments through needle exchange programs might reduce risk behaviors among IDUs. Another independent factor for HIV infection is Yi or other minority ethnicities. Majority of $\mathrm{Yi}$ and other minority people are living in remote rural areas of Xichang City and are less like to receive health education and services. Due to relatively poorer economic status and higher rate of unemployment, Yi ethnic people are more likely to be involved in drug smuggling and abuse. Intervention projects should give high priority to ethnic minority people.

This study has several limitations. First, subjects were not randomly selected; targeted sampling depends on chainreferrals (snowball sampling). IDUs who participated in 
Table I: Socio-demographic Factors Associated with HIV seropositivity among IDUs in Xichang City, Sichuan Province, China

\begin{tabular}{|c|c|c|c|c|}
\hline Factor & $N$ & $\% \mathrm{HIV}+[\mathrm{N}]$ & Odds Ratio $[95 \% \mathrm{Cl}]$ & $P$-value \\
\hline Total & 314 & $17.8[56]$ & & \\
\hline \multicolumn{5}{|l|}{ Referred by peers } \\
\hline No & 65 & $15.4[10]$ & 1.0 & \\
\hline Yes & 249 & $18.5[46]$ & $1.25[0.59,2.63]$ & 0.56 \\
\hline \multicolumn{5}{|l|}{ Sex } \\
\hline Male & 269 & $19.7[53]$ & 1.0 & \\
\hline Female & 45 & $6.7[3]$ & $0.29[0.09,0.98]$ & 0.03 \\
\hline \multicolumn{5}{|l|}{ Age } \\
\hline$<29$ years & 136 & $21.3[29]$ & 1.0 & \\
\hline$\geq 29$ years & 178 & $15.2[27]$ & $0.66[0.37,1.18]$ & 0.16 \\
\hline \multicolumn{5}{|l|}{ Ethnicity } \\
\hline Han & 192 & II.5 [22] & 1.0 & \\
\hline Other & 122 & $27.9[34]$ & $2.98[1.65,5.41]$ & $<0.01$ \\
\hline \multicolumn{5}{|l|}{ Years of education } \\
\hline$\leq 6$ & 120 & $21.7[26]$ & 1.0 & \\
\hline$>6$ & 194 & $15.5[30]$ & $0.66[0.37,1.18]$ & 0.16 \\
\hline \multicolumn{5}{|l|}{ Employed } \\
\hline Yes & 192 & $19.3[37]$ & 1.0 & \\
\hline No & 122 & $15.6[19]$ & $0.77[0.42,1.42]$ & 0.40 \\
\hline \multicolumn{5}{|l|}{ Marital Status } \\
\hline Married or cohabited & 83 & $10.8[9]$ & 1.0 & \\
\hline other & 231 & $20.4[47]$ & $2.10[0.98,4.50]$ & 0.05 \\
\hline \multicolumn{5}{|l|}{ Owning a house } \\
\hline No & 230 & $17.0[39]$ & 1.0 & \\
\hline Yes & 84 & $20.2[17]$ & $1.24[0.66,0.34]$ & 0.50 \\
\hline \multicolumn{5}{|l|}{ Yearly income in 2003} \\
\hline$<1,000$ dollars & 119 & $16.0[19]$ & 1.0 & \\
\hline$\geq 1,000$ dollars & 195 & $19.0[37]$ & $1.23[0.67,2.26]$ & 0.49 \\
\hline \multicolumn{5}{|l|}{ MMT participation } \\
\hline No & 259 & $18.5[48]$ & 1.0 & \\
\hline Yes & 55 & |4.6 [8] & $0.75[0.33,1.69]$ & 0.48 \\
\hline
\end{tabular}

MMT, methadone maintenance therapy. 
Table 2: Drug Use Behavioral Factors Associated with HIV Seropositivity among IDUs in Xichang City, Sichuan Province, China

\begin{tabular}{|c|c|c|c|c|}
\hline Factor & $\mathrm{N}$ & $\% \mathrm{HIV}+[\mathrm{N}]$ & Odds Ratio $[95 \% \mathrm{Cl}]$ & $p$-value \\
\hline \multicolumn{5}{|c|}{ During of drug injection } \\
\hline$<3$ years & 162 & $18.5[30]$ & 1.0 & \\
\hline$\geq 3$ years & 152 & $17.1[26]$ & $0.91[0.5 \mathrm{I}, 1.62]$ & 0.74 \\
\hline \multicolumn{5}{|c|}{ Using heroin in the last 3 months } \\
\hline$<7$ times/week & 112 & $17.9[20]$ & 1.0 & \\
\hline$\geq 7$ times/week & 202 & $17.8[36]$ & $1.00[0.54,1.82]$ & 0.99 \\
\hline \multicolumn{5}{|c|}{ Using heroin plus other drugs in the last 3 months } \\
\hline$<7$ times/week & 123 & $14.63[18]$ & 1.0 & \\
\hline$\geq 7$ times/week & 191 & $19.9[38]$ & $1.45[0.78,2.68]$ & 0.23 \\
\hline \multicolumn{5}{|c|}{ Injecting drugs in the last 3 months } \\
\hline$<7$ times/week & 35 & II.4 [4] & 1.0 & \\
\hline$\geq 7$ times/week & 279 & $18.6[52]$ & $1.78[0.60,5.25]$ & 0.29 \\
\hline \multicolumn{5}{|c|}{ Total times of sharing injecting equipments in the past } \\
\hline 0 times & 117 & $7.7[9]$ & 1.0 & \\
\hline I-9 times & 130 & $16.9[22]$ & $2.44[1.08,5.55]$ & \\
\hline$\geq 10$ times & 67 & $37.3[25]$ & $7.14[3.08,16.56]$ & $<0.01$ \\
\hline \multicolumn{5}{|c|}{ Number of partners sharing injecting equipments in the past } \\
\hline 0 persons & 117 & $7.7[9]$ & 1.0 & \\
\hline 1-9 persons & 157 & $22.9[36]$ & $3.57[1.64,7.75]$ & \\
\hline$\geq 10$ persons & 40 & $27.5[11]$ & $4.55[1.72,12.03]$ & $<0.01$ \\
\hline \multicolumn{5}{|c|}{ Having new partners sharing injecting equipments in the last 3 months } \\
\hline No & 251 & $14.7[37]$ & 1.0 & \\
\hline Yes & 63 & $30.2[19]$ & $2.50[1.32,4.74]$ & $<0.01$ \\
\hline \multicolumn{5}{|c|}{ Sharing needles and syringes in the last 3 months } \\
\hline No & 197 & I4.7 [29] & 1.0 & \\
\hline Yes & 117 & $23.1[27]$ & $\mathrm{I} .74[0.97,3.1 \mathrm{I}]$ & 0.06 \\
\hline \multicolumn{5}{|c|}{ Sharing rinse water in the last 3 months } \\
\hline No & 233 & $15.4[36]$ & 1.0 & \\
\hline Yes & 81 & $24.7[20]$ & I.79 [0.97, 3.33] & 0.06 \\
\hline \multicolumn{5}{|c|}{ Sharing cookers in the last 3 months } \\
\hline No & 234 & $15.4[36]$ & 1.0 & \\
\hline Yes & 80 & $25.0[20]$ & $1.83[0.99,3.40]$ & 0.05 \\
\hline \multicolumn{5}{|c|}{ Sharing cottons in the last 3 months } \\
\hline No & 301 & $17.3[52]$ & 1.0 & \\
\hline Yes & 13 & $30.8[4]$ & $2.13[0.63,7.17]$ & 0.24 \\
\hline \multicolumn{5}{|c|}{ Front-/back-loading in the last 3 months } \\
\hline No & 278 & $17.6[49]$ & 1.0 & \\
\hline Yes & 36 & $19.4[7]$ & $1.13[0.47,2.72]$ & 0.79 \\
\hline
\end{tabular}

the study may differ with those who did not; therefore, the estimate HIV prevalence may not exactly reflect the true rate in this study community. However, the sampling method is same as that in 2002 survey, and HIV prevalence rates should be comparable in these two cross-sectional surveys. Second, drug using and sexual behavioral data were based on self-reports, and recall bias and social desirability bias are possible. However, the primary outcome of this study - HIV prevalence - is based on laboratory testing. The continued increase of HIV epidemic among IDUs in Xichang City suggests that comprehensive interventions for reducing high-risk drug taking and equipment sharing behaviors are urgently needed.

\section{Competing interests}

The author(s) declare that they have no competing interests.

\section{Authors' contributions}

Lu Yin conducted data collection and analyses and drafted the manuscript. Guangming Qin was involved in study design and laboratory test. Li Zhang, Shizhu Liu, Feng Zhou, Kanglin Chen, Yunxia Wang assisted in designing the study and collecting data. Yu Zhu and Wei Hu assisted in data collection. Han-Zhu Qian and Yuhua Ruan designed the study and provided guidance on data analyses and manuscript revision. Hui Xing, Ning Wang and Yiming Shao were study consultants. Yuhua Ruan and Yiming Shao were principle investigators (PI) of these studies. All authors read and approved the final manuscript. 
Table 3: Sexual Behavioral Factors Associated with HIV Seropositivity among IDUs in Xichang City, Sichuan Province, China

\begin{tabular}{|c|c|c|c|c|}
\hline Factor & $\mathrm{N}$ & $\% \mathrm{HIV}+[\mathrm{N}]$ & Odds Ratio $[95 \% \mathrm{Cl}]$ & $p$-value \\
\hline \multicolumn{5}{|c|}{ Having heterosexual intercourses in the last 6 months } \\
\hline No & 130 & $22.3[29]$ & 1.0 & \\
\hline Yes & 184 & $14.7[27]$ & $0.60[0.34,1.07]$ & 0.08 \\
\hline \multicolumn{5}{|c|}{ Having a primary sex partner in the last 6 months } \\
\hline No & 218 & $21.1[46]$ & 1.0 & \\
\hline Yes & 96 & $10.4[10]$ & $0.43[0.21,0.90]$ & 0.02 \\
\hline \multicolumn{5}{|c|}{ Having unprotected sex with a primary sex partner in last month } \\
\hline No & 252 & $19.0[48]$ & 1.0 & \\
\hline Yes & 62 & $12.9[8]$ & $0.63[0.28,1.41]$ & 0.26 \\
\hline \multicolumn{5}{|c|}{ Having non-primary sex partners in the last 6 months } \\
\hline No & 204 & $18.6[38]$ & 1.0 & \\
\hline Yes & 110 & $16.4[18]$ & $0.85[0.46,1.58]$ & 0.62 \\
\hline \multicolumn{5}{|c|}{ Having unprotected sex with non-primary sex partners in last month } \\
\hline No & 254 & $16.1[4 \mid]$ & 1.0 & \\
\hline Yes & 60 & $25.0[15]$ & $1.73[0.88,3.40]$ & 0.11 \\
\hline \multicolumn{5}{|c|}{ Giving money for sex in the last 6 months } \\
\hline No & 250 & $19.2[48]$ & 1.0 & \\
\hline Yes & 64 & $12.5[8]$ & $0.60[0.27,1.34]$ & 0.21 \\
\hline \multicolumn{5}{|c|}{ Receiving money for sex in the last 6 months } \\
\hline No & 291 & $18.2[53]$ & 1.0 & \\
\hline Yes & 23 & $13.0[3]$ & $0.67[0.19,2.35]$ & 0.78 \\
\hline \multicolumn{5}{|c|}{ Having new sex partners in the last 6 months } \\
\hline No & 238 & $18.5[44]$ & 1.0 & \\
\hline Yes & 76 & $15.8[12]$ & $0.83[0.4 \mathrm{I}, 1.66]$ & 0.59 \\
\hline
\end{tabular}

Table 4: Multivariate Logistic Regression Analysis of Factors Associated with HIV Seropositivity

\begin{tabular}{|c|c|c|}
\hline Factor & OR $[95 \% \mathrm{Cl}]$ & $p$-value \\
\hline Ethnicity (Minorities versus Han majority) & $3.11[1.67,5.80]$ & $<0.001$ \\
\hline \multicolumn{3}{|c|}{ Total times of sharing injecting equipments in the last 3 months } \\
\hline I-9 times vs. 0 times & $2.70[1.17,6.22]$ & 0.02 \\
\hline At least 10 times vs. 0 times & $7.45[3.15,17.65]$ & $<0.001$ \\
\hline
\end{tabular}




\section{Acknowledgements}

This study was supported by grants from the National Natural Science Foundation of China (3057 I 6 I 2, 1050 1052), the Ministry of Health of China (WA2003-13) and the Ministry of Science and Technology of China (2004BA7I9A0I, 2004BA7I9A02). The authors thank all staff in the National Center for AIDS/STD Control and Prevention, Sichuan Provincial Center for Disease Control and Prevention, and Xichang Center for STD and Leprosy Control who have provided assistance in many ways. The authors are also grateful to all study participants.

\section{References}

I. Ma Y, Li ZZ, Zhang KX: HIV was first discovered among IDUsin China. Zhonghua Liu Xing Bing Xue Za Zhi 1990, I I: I84-I85.

2. The Ministry of Health of the People's Republic of China, Joint United Nations Programme on HIVIAIDS and World Health Organization: 2005 Update on the HIVIAIDS Epidemic and Response in China . January 24, 2006

3. Qian HZ, Vermund SH, Wang N: Risk of HIVIAIDS in China: Sub-population of special importance. Sex Transm Infect 2005, $81: 442-447$.

4. Ruan Y, Chen K, Hong K, He Y, Liu S, Zhou F, Qin G, Chen J, Xing H, Shao $Y$ : Community-Based Survey of HIV Transmission Modes among Intravenous Drug Users in Sichuan, China. Sex Transm Dis 2004, 31 :623-7.

5. Ruan Y, Qin G, Liu S, Qian H, Zhang L, Zhou F, He Y, Chen K, Yin L, Chen X, Hao Q, Xing H, Song Y, Wang Y, Hong K, Chen J, Shao Y: HIV incidence and factors contributed to retention in a I2month follow-up study of injection drug users in Sichuan Province, China. J Acquir Immune Deficien Syndr 2005, 39:459-63.

6. Friedman SR, Jose B, Deren S, Des Jarlais DC, Neaigus A: Risk factors for human immunodeficiency virus seroconversion among out-of-treatment drug injectors in high and low seroprevalence cities. The National AIDS Research Consortium. Am J Epidemiol 1995, I 42:864-74.

7. Des Jarlais C, Perlis T, Friedman SR, Chapman T, Kwok J, Rockwell R, Paone D, Milliken J, Monterroso E: Behavioral risk reduction in a declining HIV epidemic: injection drug users in New York City, 1990-1 997. Am J Public Health 2000, 90: I I I 2-6.

8. Chang AL: China plans to open 1000 methadone maintenance treatment clinics within 5 years 2004 [http://www.chinaids.org.cn/zhq].

9. Ouellet LJ, Thorpe LE, Huo D, Bailey SL, Jimenez AD, Johnson WA, Rahimian A, Monterroso E: Prevalence and incidence of HIV among out-of-treatment injecting drug users, Chicago I9941996. J Acquir Immune Defic Syndr 2000, 25:443-450.

10. Nelson KE, Galai N, Safaeian M, Strathdee SA, Celentano DD, Vlahov $D$ : Temporal trends in the incidence of human immunodeficiency virus infection and risk behavior among injection drug users in Baltimore, Maryland, 1988-1998. Am J Epidemiol 2002, I 56:64 |-653.

II. Rhodes T, Lowndes C, Judd A, Mikhailova LA, Sarang A, Rylkov A, Tichonov M, Lewis K, Ulyanova N, Alpatova T, Karavashkin V, Khutorskoy M, Hickman M, Parry JV, Renton A: Explosive spread and high prevalence of HIV infection among injecting drug users in Togliatti City, Russia. AIDS 2002, I 6:F25-F3I.

12. Razak MH, Jittiwutikarn J, Suriyanon V, Vongchak T, Srirak N, Beyrer C, Kawichai S, Tovanabutra S, Rungruengthanakit K, Sawanpanyalert $P$, Celentano DD: HIV prevalence and risks among injection and noninjection drug users in Northern Thailand: need for comprehensive HIV Prevention Programs. I Acquir Immune Defic Syndr 2003, 33:259-266.

13. Brogly SB, Bruneau J, Vincelette J, Lamothe F, Franco EL: Risk behaviour change and HIV infection among injection drug users in Montreal. AIDS 2000, I 4:2575-2582.

14. Koester S, Booth RE, Zhang Y: The prevalence of additional injection-related HIV risk behaviors among injection drug users. J Acquir Immune Defic Syndr Hum Retrovirol 1996, I 2:202-7.

15. Jose B, Friedman SR, Neaigus A, Curtis R, Grund JP, Goldstein MF, Ward TP, Des Jarlais DC: Syringe-mediated drug-sharing (backloading): a new risk factor for HIV among injecting drug users. AIDS 1993, 7:1653-60.

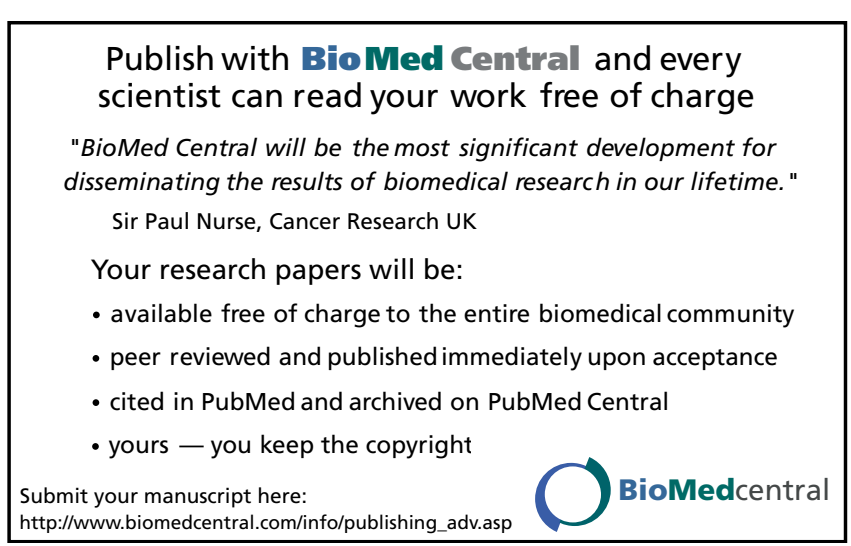

